\title{
THE GEOLOGY AND MICROPALAEONTOLOGY OF THE CHANNEL TUNNEL
}

HART, Malcolm B., Department of Geological Sciences, University of Plymouth, Drake Circus, Plymouth PL4 8AA, United Kingdom

The completed Channel Tunnel represents a major achievement of engineering construction and a tribute to many technologies - all of which combined to see the project through to a successful conclusion. As might be expected with a venture of this magnitude there was a considerable investment in geological site-investigation. Key to this investigation, however, was a major study of the Micropalaeontology. Foraminifera were used from the initial inception of the project, through the route selection phase, and - on a daily basis - throughout construction.

Beginning in 1958/9 D. J. Carter (ex-Imperial College, London) began to develop a foraminiferal zonation of the strata of Albian - Turonian age that might prove suitable for the tunnelling operation. In 1964/6 a full investigation of the route was undertaken with over 25,000 samples being studied and over 12,500,000 specimens counted and tabulated. A considerable number of boreholes were accurately correlated at that time using techniques that can only be described as a forerunner of modern graphical correlation. Once construction began samples from the cutting face, forward and downward probes were prepared on site and analysed by Dr. Colin Harris (on-site) and MBH (in Plymouth). At all times the precise location of the 9 tunnel-boring machines (TBM's) vis a vis the stratigraphy of the Upper Albian and Lower Cenomanian was known to within millimetres. When the tunnels joined (ahead of schedule) after many kilometres of undersea tunnelling they were only about $2 \mathrm{cms}$ out of alignment - and that was due to an initial surveying error. It had been assumed that sea-level at Dover and Calais was indeed level, but that proved not to be the case and the difference introduced the discrepancy.

The Channel Tunnel must represent a major triumph in the use of micropalaeontology in civil engineering, alongside the Thames Barrier and many other construction tasks in Southern England. 